\title{
El derecho a la verdad: eje fundamental de la justicia transicional en Colombia*
}

\author{
[Artículos]
}

Estefanía Acosta Páez ${ }^{* *}$

Fecha de recepción: 5 de noviembre de 2020

Fecha de aprobación: 7 de diciembre de 2020

Citar como:

Acosta Páez, E. (2021). El derecho a la verdad: eje fundamental de la justicia transicional en Colombia. Via Inveniendi Et Iudicandi, 16(1).

https://doi.org/10.15332/19090528.6481

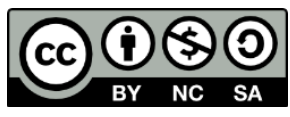

\section{Resumen}

El presente artículo tiene como finalidad realizar un estudio conceptual y normativo entorno al nacimiento, desarrollo y aplicación del derecho a la verdad en el contexto de la justicia transicional, así como los mecanismos e instituciones que materializan el derecho de las víctimas, tanto en su aspecto subjetivo como colectivo.

Palabras clave: derecho a la verdad, justicia transicional, Acuerdo Final para la Terminación del Conflicto, víctimas, Colombia.

\footnotetext{
* Este artículo hace parte del proyecto de investigación "Derecho, Estado y sociedad: transformaciones del derecho público" de la Universidad Católica de Colombia, de la línea de investigación de "Derecho administrativo" del grupo de investigación Derecho Público y TIC.

** Candidata a doctora en Derecho por la Universidad del Rosario, magíster en Derecho Público por la Université de Bordeaux (Francia), abogada por la Universidad Santo Tomás (Bogotá). Categorizada en MinCiencias como investigadora asociada. Actualmente es investigadora de la Universidad del Rosario. Correo electrónico: estefania.acostap@urosario.edu.co; ORCID: https://orcid.org/0000-0001-5131-1763
} 


\title{
The Right to Truth: a cornerstone of Transitional Justice in Colombia
}

\begin{abstract}
The purpose of this article is to carry out a conceptual and normative study of the birth, development, and application of the right to truth in the context of transitional justice, as well as the mechanisms and institutions that materialize the rights of victims, both in their subjective and collective aspects.
\end{abstract}

Keywords: right to truth, transitional justice, Final Agreement to End the Armed Conflict, victims, Colombia.

\section{Introducción}

El derecho a la verdad es un elemento connatural y un resultado objetivo, consustancial al desarrollo de todo proceso judicial que, ante todo, busca el establecimiento de la verdad con miras a determinar en justicia un acertado reconocimiento de derechos y una determinada titularidad de obligaciones resarcitorias. Además, debe garantizar el derecho de las víctimas $^{1}$, que al ser sujetos pasivos de actos de violencia generalizada y sistemática contra los más relevantes bienes jurídicos de protección constitucional $^{2}$, se ven inermes frente a una agresión ilegítima en uso de la fuerza desprovista de toda justificación; afirmación que está en perfecta concordancia con las reflexiones académicas de la noción de democracia interna (Picarella, 2018) y externa (Blanco, 2013a; Blanco, 2013b).

\footnotetext{
${ }^{1}$ Además de ser un derecho fundamental, el derecho a la verdad ha sido considerado por la doctrina como uno de los ejes fundamentales de la justicia transicional, y como eje fundamental de la reparación de las víctimas, tal y como lo señala Cáceres (2013). 2 En relación con el estado de violencia generalizada y sistemática de los derechos fundamentales de las víctimas, dichos elementos normativos son característicos de las vulneraciones de los derechos de los civiles desde mediados del siglo XX, de acuerdo con la doctrina, lo que permite dimensionar el grado de violación de dichos derechos, según Llano (2011).
}

Via Inveniendi Et Iudicandi

e-ISSN: 1909-0528 | DOI: https://doi.org/10.15332/19090528

Vol. 16 N.o 1 | enero-junio del 2021 
En este contexto específico, las garantías de las víctimas se refieren principalmente a la verdad, justicia, reparación y no repetición. El centro de estudio del presente documento es la verdad (Cortés, 2016). El derecho a la verdad es uno de los principios de la justicia transicional3, el cual busca ser garantizado en periodos de transición, construcción de paz y recuperación del tejido social (Ibáñez, 2017, p. 68). La importancia de este derecho garantiza de alguna manera que al colectivo le sean restablecidos sus derechos, especialmente el derecho a no olvidar, y a que esa verdad descubierta perdure en el tiempo para que sea aceptada por la sociedad y sea reconstruida por quienes la integran (Castro, 2016; Rincón y Peñas, 2015).

De acuerdo con Agudelo (2018), la investigación dogmática "explota de manera amplia el aspecto normativo del derecho" (p. 15). Así, pues, esta investigación indagará desde el ámbito jurídico ¿Cuál es el contenido normativo del derecho a la verdad en el marco de la justicia transicional? Para ello abordará el actual estado del derecho a la verdad y la importancia de su ejercicio para las víctimas dentro de un esquema de justicia transicional, para determinar los instrumentos tanto constitucionales como legales idóneos para su tutela efectiva, de tal manera que se garanticen los derechos de las víctimas del conflicto armado interno en Colombia (Rodríguez, 2014).

\section{Discusión y resultados}

\section{El concepto del derecho a la verdad}

Con la finalidad de comprender a cabalidad lo que constituye en la actualidad el derecho a la verdad es necesario hacer un análisis de su

\footnotetext{
${ }^{3}$ Este derecho fundamental de las víctimas ha sido eje esencial en todos los procesos de justicia transicional, particularmente en procesos de paz en países africanos, que se constituyen en los referentes más representativos, tal como lo refiere Wabgou (2013).
}

Via Inveniendi Et Iudicandi

e-ISSN: 1909-0528 | DOI: https://doi.org/10.15332/19090528

Vol. 16 N. ${ }^{\circ} 1$ | enero-junio del 2021 
advenimiento y de sus principales elementos estructurales, por lo cual, se hará 1) una breve reseña sobre su origen, 2) se analizarán sus elementos constitutivos, y 3) se estudiará la normativa aplicable en la materia.

De acuerdo con la doctrina (Naqvi, 2006) y con el Alto Comisionado de las Naciones Unidas para los Derechos Humanos (Naciones Unidas, 2006), el derecho a la verdad surge normativamente por la redacción de los artículos $32^{4}$ y $33^{5}$ del Protocolo Adicional I a los Convenios de Ginebra de 1949 (Naciones Unidas, 1977), en los que se les reconoce a las familias que han sido víctimas del enfrentamiento bélico entre dos actores beligerantes en conflicto el derecho de que se les brinde información sobre lo ocurrido a sus allegados que han desaparecido por el conflicto.

En relación con lo anterior, Fajardo (2012) reconoce que el derecho a la verdad surge con el nacimiento del derecho internacional humanitario, $\mathrm{y}$ que ha sido considerado en el derecho internacional como una norma consuetudinaria. $\mathrm{Al}$ respecto, este autor cita la Comisión Internacional de la Cruz Roja, según la cual:

El derecho a la verdad era una norma del derecho internacional consuetudinario aplicable tanto a los conflictos armados internacionales como a los internos, de modo que cada parte en el conflicto debía tomar todas las medidas factibles para conocer el paradero de las personas presuntamente desaparecidas a raíz de un conflicto armado y debían

\footnotetext{
4 "Artículo 32: Principio general. En la aplicación de la presente Sección, las actividades de las Altas Partes contratantes, de las Partes en conflicto y de las organizaciones humanitarias internacionales mencionadas en los Convenios y en el presente Protocolo deberán estar motivadas ante todo por el derecho que asiste a las familias de conocer la suerte de sus miembros" (Naciones Unidas, 1977).

5 "Artículo 33. Desaparecidos. Tan pronto como las circunstancias lo permitan, y a más tardar desde el fin de las hostilidades activas, cada Parte en conflicto buscará las personas cuya desaparición haya señalado una Parte adversa. A fin de facilitar tal búsqueda, esa Parte adversa comunicará todas las informaciones pertinentes sobre las personas de que se trate" (Naciones Unidas, 1977).
}

Via Inveniendi Et Iudicandi

e-ISSN: 1909-0528 | DOI: https://doi.org/10.15332/19090528

Vol. 16 N. ${ }^{\circ} 1$ | enero-junio del 2021 
comunicar a sus familiares todo dato de que dispusieran acerca de su suerte. (citado por Fajardo, 2012, p. 20)

Teniendo en cuenta los antecedentes referidos, el derecho internacional de los derechos humanos ha sido el encargado de dar forma al concepto del derecho a la verdad, en el contexto de los regímenes totalitarios que germinaron en América Latina a partir de los años 70 (Ibáñez, 2017, p. 191), en el marco de la comisión de desapariciones forzadas y otros crímenes que comprometieron la responsabilidad internacional del Estado (Orjuela, 2000, p. 2).

Por lo tanto, el derecho a la verdad tiene una naturaleza dual, que a su vez implica una doble titularidad que debe ser protegida. En primer lugar, aquella que reposa en cabeza de las víctimas directas de violaciones a los derechos humanos, y en segundo lugar, otra que recae en cabeza de la sociedad, de conocer la verdad de los hechos acontecidos, con la finalidad de poder acceder a los mecanismos judiciales pertinentes para obtener justicia, y, de contera, lograr una reparación legítima para las víctimas directas. Este conjunto de caracteres esenciales ha sido reconocido en la doctrina, concretamente en los Principios para la Lucha contra la Impunidad (Principios 2, 3 y 4), también llamados principios de Joinet (Naciones Unidas, 1997).

Aunado a lo anterior, tal y como lo reconoce el manifiesto en cita y ha sido puesto de presente en el derecho internacional, el derecho a la verdad "implica igualmente el deber de recordar las atrocidades acaecidas en el pasado, y se concreta en la obligación estatal de adoptar medidas adecuadas para lograr tal propósito" (Uprimny y Saffon, 2012, p. 6). Teniendo presente este reconocimiento y los contenidos estructurales que le asigna al derecho a la verdad, no se puede desconocer que, como una declaración propia del derecho internacional de carácter multilateral, no 
obliga en ninguna manera a los Estados, pero no es menos cierto, tal y como al efecto lo han resaltado Uprimny y Saffon, que dichos principios han sido reconocidos por la Comisión y la Corte Interamericana de Derechos Humanos.

Además, el derecho a la verdad se encuentra consagrado normativamente en la Convención Americana de los Derechos Humanos o Pacto de San José (OEA, 1969), puesto que el contenido de los principios anteriormente mencionados encuentra fundamento en los artículos 1, 8 y 25 de la Convención. Tales disposiciones normativas contienen obligaciones que compelen a los Estados a garantizar el respeto y el pleno ejercicio de todos los derechos reconocidos en el pacto, al debido proceso y a un recurso judicial efectivo.

Esta normativa internacional enunciada se encuentra recogida en el artículo 93 de la Constitución Política de Colombia, configurando de esta manera parte integrante del bloque de constitucionalidad. En este sentido, es necesario recabar sobre lo dicho por la Corte Constitucional, la cual ha reconocido que las normas de la Convención Americana de los Derechos Humanos hacen parte del bloque de constitucionalidad en sentido estricto y, además, que las interpretaciones realizadas por los órganos jurisdiccionales internacionales en la materia deben servir de criterio de interpretación para la aplicación de los derechos consagrados en tales instrumentos 6 .

No obstante lo anterior, desde el 2002 la Corte Constitucional ha recalcado que el derecho a la verdad constituye un derecho fundamental de las víctimas, pues

\footnotetext{
${ }^{6} \mathrm{Al}$ respecto es necesario considerar las sentencias de la Corte Constitucional C-010 de 2000, C-251 de 1997 y T-786 de 2003, entre otras.
}

Via Inveniendi Et Iudicandi

e-ISSN: 1909-0528 | DOI: https://doi.org/10.15332/19090528

Vol. 16 N. ${ }^{\circ} 1$ | enero-junio del 2021 
ha reconocido su carácter de tal en diversas oportunidades, al manifestar que los derechos de las víctimas en los procesos penales desbordan la pretensión eminentemente indemnizatoria o patrimonial de reparación y, al corresponder a un concepto de reparación más integral, incluyen también el derecho a la verdad y el derecho a la justicia. (C. C., Sentencia C-282 de 2002)

Teniendo en cuenta el concepto del derecho a la verdad y sus ejes estructurales, es necesario analizar su regulación y su marco de aplicación en el derecho internacional para poder entender claramente sus formas de interpretación y aplicación en el marco de la justicia transicional.

En concordancia con lo dispuesto anteriormente, y a pesar de no ser el fundamento principal del presente artículo, resulta de interés resaltar el contexto de los derechos humanos desde el escenario del derecho constitucional, para lo cual la doctrina ha establecido diferencias sobre el particular (Barreto, 2014; Barreto, 2018), reflejando que es el reconocimiento del papel jurídico de los derechos humanos y su incidencia frente al fenómeno de la globalización.

Ahora bien, el problema de investigación planteado en este artículo supone reiterar que la naturaleza jurídica de la noción de Estado ha sido contextualizada académicamente desde diferentes perspectivas, las cuales ya no se concentran solo en el escenario interno (Blanco, 2019; Scocozza, 2015), sino también en el escenario externo.

\section{El derecho a la verdad en el marco de la justicia transicional}

Una vez definidos el alcance y el contenido del derecho a la verdad tanto en el ámbito nacional como internacional, es necesario establecer su relevancia dentro del marco de la justicia transicional, más aun después de la firma del "Acuerdo Final para la Terminación del Conflicto y la 
Construcción de una Paz Estable y Duradera” y con la implementación de la Jurisdicción Especial para la Paz (JEP).

En este contexto, se hace indispensable articular la noción del derecho a la verdad, teniendo como objetivo su aplicación dentro de los esquemas de justicia transicional y las herramientas diseñadas dentro de este, como la Comisión de la Verdad y otros instrumentos que permiten su aplicación. Con tal objetivo, 1) se hará una definición del concepto de justicia transicional, 2) se abordará la necesidad del establecimiento de la verdad como eje esencial de los procesos que se adelantan en su marco, y 3) se definirá cuál es el rol de las víctimas y de qué forma pueden hacer efectivo su derecho a la verdad en el marco de dichos procedimientos.

En primer lugar, la justicia transicional ha sido definida por la doctrina como "el conjunto de herramientas empleadas por países que dejan atrás periodos de conflicto y represión para enfrentarse a violaciones de derechos humanos masivas o sistemáticas, de tal magnitud y gravedad que el sistema judicial convencional no puede darles una respuesta adecuada" (Centro Internacional para la Justicia Transicional, s. f.).

Adicionalmente, la doctrina la ha definido como "el tipo de arreglos judiciales y extrajudiciales que facilitan y permiten la transición de un régimen autoritario a una democracia o de una situación de guerra a una de paz" (Rettberg, 2005, p. 1).

En tal sentido, se deben precisar las diferentes formas en las que la verdad puede ser reconocida dentro de los esquemas de justicia transicional, dependiendo de los escenarios en los cuales esta se desarrolle. De acuerdo con lo anterior, existen tres conceptos de verdad en este tipo de procesos sociales y normativos:

(i) la verdad judicial, esto es, la verdad oficial de lo sucedido alcanzada a través de un proceso judicial, ya sea porque fue declarada por éste, o se

Via Inveniendi Et Iudicandi

e-ISSN: 1909-0528 | DOI: https://doi.org/10.15332/19090528

Vol. 16 N. ${ }^{\circ} 1$ | enero-junio del 2021 
puede inferir del mismo; (ii) los mecanismos extrajudiciales

institucionalizados de búsqueda de la verdad, que consisten en espacios

especialmente creados y reconocidos institucionalmente para la

reconstrucción histórica de la verdad, y cuyo prototipo son las

comisiones de verdad; y (iii) las verdades sociales no institucionalizadas, es decir, todas aquellas formas de reconstrucción de la verdad y

preservación de la memoria colectiva llevadas a cabo por instancias no

institucionales, tales como historiadores, periodistas, literatos y

científicos sociales, entre otros. (Uprimny y Saffon, 2006, p. 235)

En segundo lugar, la aspiración de las normas jurídicas de justicia transicional, y en particular las que se han implementado en Colombia con ocasión de la terminación del conflicto armado con las Fuerzas Armadas Revolucionarias de Colombia (FARC-EP), tienen como derrotero el establecimiento de la verdad como requisito esencial de acceso de los grupos que deponen las armas y que hacen su tránsito a la legalidad a los beneficios en él contemplados. En este sentido, la verdad se articula de forma inescindible con el establecimiento de las consecuencias jurídicas de las graves violaciones a los derechos humanos.

De esta manera, teniendo en cuenta la satisfacción a plenitud del derecho a la verdad, el Acuerdo Final para la Terminación del Conflicto estableció como un principio el esclarecimiento de la verdad, según el cual:

Esclarecer lo sucedido a lo largo del conflicto, incluyendo sus múltiples causas, orígenes y sus efectos, es parte fundamental de la satisfacción de los derechos de las víctimas, y de la sociedad en general. La reconstrucción de la confianza depende del esclarecimiento pleno y del reconocimiento de la verdad. (2017, p. 113)

En este escenario, uno de los ejes axiológicos fundamentales de la justicia transicional es el derecho a la verdad, tanto colectivo, como individual. De su materialización depende la definición de las consecuencias jurídicas del 
sometimiento de los miembros de las FARC-EP a la Jurisdicción Especial para la Paz, puesto que en la medida en que reconozcan lo acontecido será directamente proporcional la pena que recibirán.

Ante lo anterior, es necesario aclarar que el Acuerdo Final dispuso de tres tipos de sanciones a quienes se sometan a la JEP: 1) las sanciones propias, 2) las sanciones alternativas y 3) las sanciones ordinarias, las cuales dependen en su graduación punitiva y aplicación, del grado de verdad que reconozcan los actores de las graves violaciones a los derechos humanos. En este sentido:

1. Las sanciones propias: tienen un componente restrictivo y reparador, y se impondrán a aquellos autores de graves violaciones a los derechos humanos que reconozcan la verdad sobre lo acontecido y su responsabilidad. Este tipo de sanciones serán restrictivas de ciertos derechos como la libertad de movimiento y residencia, y podrán tener una duración de entre 5 y 8 años.

2. Las sanciones alternativas: serán aplicables a los autores de graves atentados contra los derechos humanos que reconozcan tardíamente la verdad de lo ocurrido, y que acepten su responsabilidad. Consisten exclusivamente en pena privativa de la libertad entre 5 y 8 años.

3. Las sanciones ordinarias: son aplicables a quien no hayan reconocido su responsabilidad individual por lo acontecido y no hayan accedido a decir oportunamente la verdad sobre los crímenes por los cuales se les procesa. Esta sanción, al igual que la anterior, tiene una función estrictamente retributiva y consistirá en pena privativa de la libertad de 15 a 20 años.

Con fundamento en lo anterior, el Acuerdo Final dispone que:

[...] el reconocimiento de verdad y responsabilidad de las conductas podrá hacerse de manera individual y colectiva, de forma oral o mediante

Via Inveniendi Et Iudicandi

e-ISSN: 1909-0528 | DOI: https://doi.org/10.15332/19090528

Vol. 16 N. ${ }^{\circ} 1$ | enero-junio del 2021 
escrito remitido a la Sala de Reconocimiento de Verdad y

Responsabilidad de la JEP, una vez instalada la Sala.

En tercer lugar, sobre los derechos de las víctimas, en relación con los procedimientos para el reconocimiento de la verdad y la aceptación de responsabilidad de los autores de graves violaciones a los derechos humanos en el marco de la justicia transicional, las víctimas pueden participar de forma activa para que su derecho legítimo a la verdad individual y colectiva sea tutelado. En virtud de ello, el artículo $27 \mathrm{D}$ de la Ley 1922 de 2018, "Por medio de la cual se adoptan unas Reglas de Procedimiento para la Jurisdicción Especial para la Paz", dispone las acciones que estas pueden efectuar en el proceso de establecimiento de la verdad. Entre tales acciones se encuentran las siguientes:

1. Presentar informes por medio de organizaciones de víctimas y de derechos humanos.

2. Ser oídas en los supuestos de priorización y selección de casos.

3. Respecto de la garantía de priorización, las víctimas podrán participar con observaciones a través de sus organizaciones.

4. Aportar pruebas y, con posterioridad a la recepción de versiones voluntarias, presentar observaciones a estas y recibir copia del expediente.

5. Asistir a la Audiencia Pública de Reconocimiento y dentro de los 15 días hábiles posteriores, presentar observaciones finales escritas sobre todos los aspectos concernientes a la resolución de conclusiones.

6. Presentar observaciones en relación con los proyectos restaurativos presentados por la persona compareciente.

7. Las víctimas de violencia basada en género, incluyendo aquellas de violencia sexual, tienen derecho a no ser confrontadas con su agresor. 
Como corolario de todos los instrumentos mencionados anteriormente, en el actual marco de justicia transicional, se ha diseñado un Sistema Integral de Verdad, Justicia, Reparación y No Repetición (SIVJRNR), que contiene las herramientas de articulación del derecho a la verdad, y los procedimientos en el marco del Acuerdo Final para la Terminación del Conflicto. Dicho sistema tiene como fundamento el derecho a la verdad, el cual la reconoce como eje esencial en los siguientes términos:

El Sistema Integral parte del principio del reconocimiento de las víctimas como ciudadanos con derechos; del reconocimiento de que debe existir verdad plena sobre lo ocurrido. (Ibáñez, 2017, p. 70)

Aunado a las herramientas de orden procedimental antes enunciadas, en el marco de la justicia transicional y como parte del SIVJRNR, se han creado cinco mecanismos que tienen como finalidad la materialización de las herramientas dispuestas para el reconocimiento de los derechos de las víctimas, y en particular el derecho a la verdad, las cuales están compuestas por:

1. La Comisión para el Esclarecimiento de la Verdad, la Convivencia y la No Repetición.

2. La Unidad Especial para la búsqueda de personas dadas por desaparecidas en el contexto del conflicto armado.

3. La Jurisdicción Especial para la Paz.

4. Las Medidas de Reparación Integral para la Construcción de la Paz.

5. Las Garantías de no Repetición.

Dentro de todo este marco institucional creado por el Acuerdo Final para la Terminación del Conflicto Armado, es importante reconocer que la institución que por excelencia está dedicada a la aplicación de instrumentos jurídicos para la protección y tutela del derecho a la verdad 
es la Comisión para el Esclarecimiento de la Verdad, la Convivencia y la No Repetición.

En palabras del Acuerdo Final, y resaltando su compromiso con el esclarecimiento de la verdad en el marco de la Justicia Transicional, esta Comisión

Será un órgano temporal y de carácter extra-judicial, que busca conocer la verdad de lo ocurrido y contribuir al esclarecimiento de las violaciones e infracciones y ofrecer una explicación amplia a toda la sociedad de la complejidad del conflicto (derecho a la verdad colectiva); promover el reconocimiento de las víctimas y de las responsabilidades de quienes participaron directa e indirectamente en el conflicto armado; y promover la convivencia en los territorios para garantizar la no repetición. (p. 117)

Teniendo en cuenta las finalidades de la Comisión antes señalada, de acuerdo con lo analizado en este documento y lo reconocido por la doctrina (Uprimny y Saffon, 2006), este tipo de mecanismos son idóneos para el reconocimiento de los derechos de las víctimas. En este sentido, la verdad que emane en aplicación del procedimiento legal se enmarca en el contexto de una verdad institucional extrajudicial, que si bien permite, mediatamente, viabilizar el trabajo de los órganos jurisdiccionales, permite también una materialización inmediata y un resarcimiento efectivo del derecho a la verdad de las víctimas. Lo dispuesto en las líneas anteriores esta reiterado por gran parte de la doctrina colombiana (Picarella, 2017).

\section{Mecanismos jurídicos de protección y materialización del derecho a la verdad de las víctimas dentro del SIVJRNR}

Teniendo en cuenta lo hasta aquí señalado, además de hacer un análisis del arquetipo institucional con el que cuenta el SIVJRNR - contenido por el Acto Legislativo 01 de 2017, por medio del cual se creó un entramado 
institucional con el propósito de implementar a plenitud el Acuerdo Final para la Terminación del Conflicto, firmado entre el Gobierno y las FARCEP, el 26 de noviembre de 2016, a efectos de verificar el ámbito de competencia material de las instituciones de la justicia transicional para materializar el derecho a la verdad de las víctimas-, es importante destacar que la garantía del derecho a la verdad tiene varias fases para su consolidación. En palabras de la Corte Constitucional y de la Corte IDH, esta tiene dos ámbitos de aplicación, siendo al mismo tiempo derecho de naturaleza colectivo y subjetivo (Llano, 2013).

Por lo tanto, para su plena satisfacción, y teniendo en cuenta las fases de su concreción, el derecho a la verdad se materializa, primero, en una etapa preliminar de recopilación y validación de información, que se puede denominar reconstrucción de contexto general, en la cual cualquiera de las entidades creadas para el efecto en procesos de justicia transicional se encarga de establecer los antecedentes, el contexto, los actores enfrentados en el conflicto y cómo estaban constituidos, las diferentes formas de las conductas criminales y los lugares o aspectos geográficos de tales conductas, entre otros aspectos.

En una segunda etapa - y con fundamento en información recaudada de manera preferente por órganos facultados para abordar el estudio de las circunstancias modales de la verdad contextual de los hechos, como pueden serlo, las Comisiones de la Verdad- esta información privilegiada puede ser usada por las víctimas o bien puede servir de fundamento por otras autoridades, en este caso con facultades jurisdiccionales, para determinar con precisión en cada caso concreto cómo se cometieron las violaciones a los derechos de las víctimas. De esta manera se trata de establecer en cada caso, con precisión, las circunstancias de tiempo, modo y lugar de las conductas criminales para permitir establecer la verdad de 
los hechos y determinar el grado de responsabilidad individual de los autores.

Teniendo en cuenta estos dos momentos, el SIVJRNR implementado por el Acuerdo Final ha creado dos organismos que contribuyen y dan respuesta a estas dos etapas: la Comisión de la Verdad, la cual está encargada de establecer las circunstancias contextuales que encarnan la verdad de lo hechos de forma contextual, y la Jurisdicción Especial para la Paz, la cual cuenta con la competencia material para adelantar la investigación, juicio y sanción de los autores de las conductas punibles cometidas en el marco del conflicto armado, y de esta manera establecer la verdad de cada caso.

Por la importancia de estos dos órganos, en la presente investigación se hará un estudio de su competencia material en el marco de las normas jurídicas que regulan su funcionamiento, con el propósito de validar la hipótesis de investigación y, de esta manera, comprobar que la Comisión de la Verdad tiene la función de garantizar los derechos colectivos de las víctimas del conflicto y de la sociedad en general, y que, en contraste, la Jurisdicción Especial para la Paz tiene como misión establecer la verdad de cada caso en concreto.

Teniendo como derroteros los ejes temáticos ya enunciados, en materia de protección de los derechos de las víctimas, el Acuerdo Final dedicó el punto 5 de su cuerpo normativo a desarrollar este eje esencial, creando el Sistema Integral de Verdad, Justicia, Reparación y No Repetición, y todo el conjunto de herramientas orgánicas, jurídicas y procedimentales que componen la Jurisdicción Especial para la Paz. Este entramado normativo e institucional, parte de la necesidad de reconocimiento de dos ejes esenciales en relación con las víctimas: sus derechos humanos y el derecho a la verdad del que son titulares. En este sentido se ha desarrollado un conjunto de principios que irradian la interpretación, intelección y 
correcta aplicación de las disposiciones contenidas en el marco de la justicia transicional.

La materialización de estos principios es el SIVJRNR, el cual está integrado por cinco mecanismos y medidas, tal y como se consagró en el Acuerdo Final, las cuales incluyen la creación de la Comisión para el Esclarecimiento de la Verdad, la Convivencia y la No Repetición (en adelante Comisión de la Verdad), la cual se constituye como un organismo de carácter extrajudicial, de naturaleza temporal, que tiene como finalidad dar explicación tanto a la sociedad como a las víctimas de la complejidad de los hechos ocurridos en el transcurso del conflicto armado, a través del esclarecimiento y conocimiento de la verdad de lo ocurrido, estableciendo cómo acaecieron las graves violaciones a los derechos humanos.

Una vez agotada esta primera fase, los hechos determinados con claridad por la Comisión de la Verdad servirán para establecer la responsabilidad de los autores de graves violaciones a los derechos humanos, al logro de la reconciliación y la recomposición del tejido social en las regiones que han sido afectadas por la violencia en el transcurso del conflicto armado, con lo que se busca que tales situaciones no se repitan en el futuro.

Una vez delimitado el objetivo de la Comisión de la Verdad, sus labores deben articularse con todo el conjunto de acciones y herramientas administrativas y judiciales que se han desarrollado en el marco del SIVJRNR, pues, tal como lo describen las disposiciones del Acuerdo Final, es el mecanismo más idóneo para responder a "la necesidad ética, política e histórica de contribuir, junto con otras iniciativas, a crear condiciones, los compromisos y las garantías de no repetición".

En este sentido, la Comisión de la Verdad deberá cumplir con tres objetivos fundamentales: 1) esclarecer lo ocurrido, especialmente de las violaciones de derechos humanos de niños, niñas y adolescentes; 2 
promover y contribuir al logro del reconocimiento de la calidad de las víctimas como sujetos políticos e integrantes de la sociedad civil, en tanto ciudadanos y ciudadanas, y, aunado a lo anterior, la determinación de la responsabilidad de los autores de los graves atentados en contra de los derechos humanos perpetrados en el marco del conflicto armado, lo cual se concreta tanto en un reconocimiento de naturaleza colectiva como individual; 3) promover la convivencia en los territorios, posibilitando escenarios de resolución pacífica de los conflictos, en un marco de tolerancia y de reivindicación democrática.

El desarrollo de un enfoque diferencial en la labor de la Comisión de la Verdad, en los términos del Acuerdo Final, será la única forma de que la sociedad colombiana reconozca los mecanismos históricos de discriminación y estigmatización que deben ser desarraigados de los imaginarios colectivos y sociales con la finalidad de que se logre finalmente un respeto del otro a partir de la diferencia.

Según lo anterior, los criterios orientadores que tendrá la Comisión de la Verdad en el ejercicio de sus funciones constituirán 1) la centralidad de las víctimas, 2) la imparcialidad e independencia, 3) su naturaleza transitoria, 4) la participación tanto de víctimas como de victimarios, 5) un enfoque territorial, 6) un enfoque diferencial y de género, 7) una coordinación con otras medidas de construcción de paz, 8) garantías para los comisionados y las comisionadas, 9) condiciones de seguridad, 10) estándares de convivencia y reconciliación, 11) el establecimiento de reglas de procedimiento, 12) el establecimiento de una metodología de recolección de información y, 13) su naturaleza de mecanismo extrajudicial. Tomando como marco de referencia estos criterios orientadores, la Comisión de la Verdad tendrá la competencia material de establecer el esclarecimiento de los siguientes hechos relevantes para determinar las 
situaciones que resarcirán el derecho a la verdad de las víctimas y la sociedad, en el marco de la implementación del Acuerdo Final:

- Hechos ocurridos en el marco del conflicto armado que constituyen graves violaciones a los derechos humanos y graves infracciones al derecho internacional humanitario (DIH), destacando aquellas que tienen carácter masivo y sistemático.

- La responsabilidad colectiva del Estado, las entidades y las autoridades públicas, de los miembros de las FARC-EP, de los paramilitares y otras organizaciones ilícitas que hayan cometido graves atentados contra los derechos humanos y contra las normas del derecho internacional humanitario.

- El impacto humano y social del conflicto armado, particularmente en relación con el ejercicio de los derechos económicos, sociales y culturales, y las formas diferenciadas de maltrato en contra de mujeres, niños, niñas, adolescentes, jóvenes y adultos mayores, a personas en relación de su religión, opiniones o creencias, a las personas en situación de discapacidad, miembros de la comunidad LGBTI, entre otros.

- El impacto de las acciones desplegadas en virtud del conflicto sobre el ejercicio de la política y el funcionamiento de los mecanismos democráticos, con especial énfasis en los efectos producidos por tales acciones en los partidos políticos de la oposición.

- El impacto de las acciones llevadas a cabo en medio del conflicto a los actores de la violencia desplegada, tales como los combatientes, sus familias y entornos sociales.

- El contexto histórico y las causas del conflicto armado interno, para lo cual, la Comisión de la Verdad debe tener en cuenta los informes de la Comisión Histórica del Conflicto y sus víctimas. 
- Las condiciones que permitieron la persistencia y continuación del conflicto, teniendo en cuenta como insumo los informes de la Comisión Histórica del Conflicto y sus víctimas.

- El establecimiento de los hechos que se llevaron a cabo durante el desarrollo del conflicto, en particular de los agentes del Estado y de las organizaciones al margen de la ley.

- La definición de las causas y orígenes del fenómeno del paramilitarismo, y las formas en que este tipo de organizaciones se manifiestan, sus formas de organización, financiación, y el impacto de sus acciones.

- El desplazamiento y despojo de tierras con ocasión del conflicto y sus consecuencias.

- La relación histórica y actual del conflicto armado con el sustento, financiación y pervivencia de cultivos ilícitos, la producción y comercialización de drogas ilícitas, y de hechos constitutivos de lavado de activos.

- Las experiencias de fortalecimiento del tejido social en las comunidades y las experiencias de resiliencia individual o colectiva, al igual que los procesos de transformación positiva de las organizaciones e instituciones a lo largo del conflicto.

Teniendo como fundamento las diferentes situaciones fácticas que conforman la competencia material de determinación de la Comisión de la Verdad, el Acuerdo Final para la terminación del Conflicto ha definido como extremos temporales para la investigación y el establecimiento de dichas circunstancias la duración del conflicto armado interno. No obstante, esta temporalidad extensa no es óbice para que la Comisión pueda establecer las causas del conflicto armado, y analizar e indagar acerca de la ocurrencia y condiciones particulares de situaciones pretéritas o posteriores a este. 
Con la finalidad de determinar el conjunto de situaciones fácticas anteriormente descritas, la Comisión de la Verdad tendrá como funciones:

- Indagar e investigar sobre el conjunto de hechos anteriormente reseñados a través de "metodologías y formas de recolección de análisis de información que sean necesarias para tal efecto, considerando las generalmente aceptadas por las ciencias sociales, y teniendo en cuenta los anteriores esfuerzos de construcción de la verdad, incluyendo como insumo básico, entre otros, los informes de la Comisión Histórica del Conflicto y sus Víctimas" (Decreto 588 de 2017, art 13).

- La creación de espacios a nivel nacional, regional y territorial donde se puedan llevar a cabo audiencias públicas de carácter temático, con enfoque territorial, en el que se cuente con la participación de las víctimas, tanto a nivel individual como colectivo, y de diferentes actores sociales.

- Los espacios anteriormente referidos podrán incluir escenarios públicos de "discusión y reflexión o ceremonias culturales", con la finalidad de que quienes hayan participado en el conflicto tengan la posibilidad de hacer actos de reconocimiento de responsabilidad, pedir perdón y ofrecer explicaciones sobre las conductas delictivas realizadas.

- La elaboración de informes que determinen el establecimiento de los diferentes contextos de ocurrencia de los hechos y las conclusiones y recomendaciones de su trabajo. "El informe de la Comisión será presentado de manera oficial mediante acto público a las ramas del poder público y al conjunto de la sociedad colombiana” (Ibáñez, 2017, p. 45).

- Desempeñar labores de orientación a las víctimas y a las comunidades que participen en las acciones, herramientas y planes para la defensa y materialización de sus derechos. 
- La implementación de una estrategia de difusión, pedagogía y relacionamiento activo con los medios de comunicación para dar cuenta de los avances y desarrollos de la Comisión en cumplimiento de sus funciones, con la finalidad de asegurar la mayor participación posible.

- La adopción de medidas para el archivo de la información recolectada sobre las labores desempeñadas, y tomar las medidas necesarias para asegurar su preservación.

- "Asegurar la transversalidad del enfoque de género, en todo el ámbito de trabajo de la Comisión, con la creación de un grupo de género que contribuya con tareas específicas de carácter técnico, de investigación, preparación de audiencias, entre otras" (Ibáñez, 2017, p. 87).

- Rendir cuentas a la sociedad de forma periódica, al menos semestralmente, sobre las actividades desarrolladas.

- Darse su propio reglamento y programa de trabajo.

Una vez definidas las funciones y ejes estructurales de la Comisión de la Verdad, establecidas en el Acuerdo Final para la Terminación del Conflicto, es necesario aludir su régimen de implementación, el cual fue establecido por el Decreto 588 de 2017, en el que se reguló la forma jurídico-operativa en la cual habría de funcionar la Comisión. En este sentido, el artículo 1 de dicho decreto dispuso que la Comisión de la Verdad sería un "ente autónomo e independiente del orden nacional, de rango constitucional, con personería jurídica, con autonomía administrativa, presupuestal y técnica, sujeto a un régimen legal propio, por un periodo de tres años de duración”. Por otro lado, su estructura orgánica estaría compuesta por un presidente, "de conformidad con los lineamientos del pleno de comisionados", cuyas funciones administrativas y directivas están consagradas en el artículo 21 del Decreto 588 de 2017, el cual contará con el apoyo de un secretario general, quien tiene como 
función principal la administración de la Comisión, y que será designado por los comisionados para cumplir las funciones establecidas en el artículo 22.

Por su parte, la Comisión de la Verdad estará compuesta por 11 comisionados, incluyendo a su presidente, los cuales, de acuerdo con lo normado en el artículo 24 del Decreto 588 de 2017, "serán elegidos por el Comité de Escogencia establecido en el artículo transitorio 7 del Acto Legislativo 01 de 2017". Aunado a lo anterior, se debe mencionar que los recursos y el patrimonio con el cual se financiará la Comisión de la Verdad, en virtud del artículo 30 del Decreto 588 de 2017, provendrán de los siguientes rubros:

1. Los recursos del Presupuesto General de la Nación que se le asignen.

2. Las donaciones públicas o privadas para el desarrollo de los objetivos de la Comisión de la Verdad.

3. Los aportes de cualquier clase provenientes de recursos de cooperación internacional para el cumplimiento del objetivo de la Comisión de la Verdad.

4. Los demás que reciba en desarrollo de su objeto.

Además, a la Comisión de la Verdad, en el marco de su desarrollo funcional, no le son oponibles "las reservas en materia de acceso a la información pública frente a las violaciones de derechos humanos o infracciones al Derecho Internacional Humanitario”, según el artículo 21 de la Ley Estatutaria de Transparencia y Derecho de Acceso a la Información Pública Nacional, Ley 1712 de 2014.

Por otra parte, y en concordancia con lo anterior, la competencia de la Jurisdicción Especial para la Paz se concreta en administrar justicia de forma exclusiva, autónoma y preferente de las conductas: 
1. Cometidas con anterioridad al 1 de diciembre de 2016, por causa, con ocasión o en relación directa o indirecta con el conflicto armado.

2. De las conductas cometidas por las personas que participaron en el conflicto armado, en especial respecto a conductas consideradas graves infracciones al derecho internacional humanitario o graves violaciones de derechos humanos.

3. La JEP asumirá la competencia en los términos del artículo 6 de la Ley 1922 de 2018, de las actuaciones penales, disciplinarias o administrativas por conductas cometidas con ocasión, por causa o en relación directa o indirecta con el conflicto armado.

4. De acuerdo con la Sentencia C-o8o de 2018 de la Corte Constitucional, la JEP tiene competencia para conocer todos los delitos de ejecución permanente, así como los estrechamente relacionados con el proceso de dejación de armas.

Además de lo anterior, es menester señalar que la Corte Constitucional, a efectos de determinar la competencia de la JEP, ha señalado que los casos sometidos a su conocimiento deben contener los siguientes criterios:

1. "Que el conflicto armado haya sido causa directa o indirecta de la comisión de la conducta punible $o$,

2. Que la existencia del conflicto armado haya influido en el autor, partícipe o encubridor de la conducta punible cometida por causa, con ocasión o en relación directa o indirecta con el conflicto, en cuanto a:

1. Su capacidad de cometerla, es decir, a que por razón del conflicto armado el perpetrador haya adquirido habilidades mayores que le sirvieron para ejecutar la conducta.

2. Su decisión para cometerla, es decir, a la resolución o disposición del individuo para cometerla. 
3. La manera en que fue cometida, es decir, a que, producto del conflicto armado, el perpetrador de la conducta haya tenido la oportunidad de contar con medios que le sirvieron para consumarla.

4. La selección del objetivo que se proponía alcanzar con la comisión del delito". (artículo transitorio 23 del Acto Legislativo 01 de 2017)

\section{Conclusiones}

De acuerdo con el análisis, en aplicación de las normas creadas para la terminación del conflicto armado interno en Colombia, existen normas y mecanismos jurídicos en aplicación de la justicia transicional que permiten el respeto y la garantía del derecho a la verdad de las víctimas del conflicto, a través de dos arquetipos institucionales: la Comisión de la Verdad y la Jurisdicción Especial para la Paz. Estas instituciones protegen el derecho a la verdad en sentido colectivo y subjetivo, el primero de ellos desde la construcción de la verdad de lo acaecido en el conflicto desde un aspecto contextual, y, el segundo, estableciendo la verdad jurídica en cada caso concreto.

A través del estudio realizado, se encontró que el contenido del derecho a la verdad en el marco de la justicia transicional resulta un eje fundamental para la construcción de paz, más allá de los mecanismos de justicia. Con la consolidación del derecho a la verdad se realiza un acertado reconocimiento de derechos y se garantiza a las víctimas el esclarecimiento de los hechos ocurridos en el marco del conflicto.

No obstante lo anterior, más allá del reconocimiento conceptual, normativo y jurisprudencial, el gran reto para el caso de Colombia es la materialización del derecho a la verdad a través de las instituciones creadas para tal fin y de los procesos judiciales. Las fases de su concreción son: 1) en una etapa preliminar de recopilación y validación de información, 2) el estudio de las circunstancias modales de la verdad de 
los hechos y 3) el análisis de los resultados de acuerdo con la satisfacción del derecho a la verdad de las víctimas.

Finalmente, como se mencionó, los mecanismos garantistas dependen de la Comisión de la Verdad bajo los criterios orientadores de 1) la centralidad de las víctimas, 2) la imparcialidad e independencia, 3) la participación de víctimas y de victimarios, 4) un enfoque territorial, un enfoque diferencial y de género, 5) una coordinación con otras medidas de construcción de paz, 6) garantías para los comisionados y las comisionadas, 7) estándares de convivencia y reconciliación y 8) el establecimiento de una metodología de recolección de información.

\section{Referencias}

Acuerdo Final para la Terminación del Conflicto y la Construcción de una Paz Estable y Duradera. 24 de noviembre de 2016.

https://www.jep.gov.co/Documents/Acuerdo\%20Final/Acuerdo\%20Final\%20Firma do.pdf

Agudelo, O. (2018). La pregunta por el método: derecho y metodología de la investigación. Editorial Universidad Católica de Colombia.

Barreto, J. M. (2014). Epistemologies of the south and human rights: Santos and the quest for global and cognitive justice. Indiana Journal of Global Legal Studies, 21(2), 398422.

Barreto, J. M. (2018). Decolonial thinking and the quest for decolonising human rights. Asian Journal of Social Science, 46(4-5), 484-502.

Blanco, C. (2013a). Aproximación a la noción de soberanía estatal en el marco del proceso andino de integración. Revista Republicana, 15, 34-56.

Blanco, C. (2013b). Algunas propuestas frente a la crisis de legitimidad de la Comunidad Andina. Análisis Político, 26(78), 23-45.

Blanco, C. (2019). El ámbito del derecho en la descentralización territorial colombiana y la Comunidad Andina (CAN). Revista Republicana, 26, 93-108.

Via Inveniendi Et Iudicandi

e-ISSN: 1909-0528 | DOI: https://doi.org/10.15332/19090528

Vol. 16 N. ${ }^{\circ} 1$ | enero-junio del 2021 
Cáceres, E. (2013). Justicia transicional y derecho a la reparación integral. Aproximación al caso colombiano. Revista Novum Jus, 7(2), 57-87.

Castro, A. M. (2016). Derecho a la intimidad en las redes sociales de internet en Colombia. Novum Jus, 1O(1), 113-133. https://doi.org/10.14718/NovumJus.2016.10.1.5

Centro Internacional para la Justicia Transicional. (s. f.). ¿Qué es la justicia transicional? https://www.ictj.org/es/que-es-la-justicia-transicional

Colombia. Acto Legislativo 01 de 2017. Por medio del cual se crea un título de disposiciones transitorias de la Constitución para la terminación del conflicto armado y la construcción de una paz estable y duradera y se dictan otras disposiciones. 4 de abril de 2017. Diario Oficial n. ${ }^{\circ} 50.196$.

Colombia. Decreto Ley 588 de 2017. Por el cual se organiza la Comisión para el Esclarecimiento de la Verdad, la Convivencia y la no Repetición. 5 de abril de 2017. Diario Oficial n. ${ }^{\circ} 50.197$.

Colombia. Ley 1712 de 2014. Por medio de la cual se crea la Ley de Transparencia y del Derecho de Acceso a la Información Pública Nacional y se dictan otras disposiciones. 6 de marzo de 2014. Diario Oficial n. ${ }^{\circ} 49.084$.

Colombia. Ley 1922 del 18 de julio de 2018. Por medio de la cual se adoptan unas Reglas de Procedimiento para la Jurisdicción Especial para la Paz. 18 de julio de 2018. Diario Oficial n. ${ }^{\circ} 50.658$.

Corte Constitucional de Colombia. 28 de mayo de 1997, M. P.: A. Martínez, Sentencia C-251 de 1997.

Corte Constitucional de Colombia. 19 de enero de 2000, M. P.: A. Martínez, Sentencia C-010 de 2000.

Corte Constitucional de Colombia. 3 de abril de 2002, M. P.: M. J. Cepeda Espinosa y E. Montealegre Lynett, Sentencia C-282 de 2002.

Corte Constitucional de Colombia. 11 de septiembre de 2003, M. P.: M. Monroy, Sentencia T786 de 2003.

Corte Constitucional de Colombia. 15 de agosto de 2018, M. S.: A. Lizarazo, Sentencia C-o80 de 2018. 
Corte Interamericana de Derechos Humanos. (2002). Sentencia Caso Bámaca Velásquez Vs. Guatemala. Sentencia del 22 de febrero de 2002. Reparaciones y Costas. http://www.corteidh.or.cr/docs/casos/articulos/Seriec 91 esp.pdf

Cortés, S. (2016). Derechos humanos en las políticas de paz y posconflicto en Colombia. Revista Via Inveniendi et Iudicandi, 11(1), 129-145. https://doi.org/10.15332/s19090528.2016 .0001 .03

Fajardo, L. (2012). Elementos estructurales del derecho a la verdad. Revista Civilizar, 12(22), 15-34. https://revistas.usergioarboleda.edu.co/index.php/ccsh/article/view/89

Ibáñez, J. (2017). Justicia transicional y las comisiones de la verdad. Instituto Berg.

Llano, J. (2011). Apuntes para la comprensión del conflicto armado colombiano contemporáneo. Revista Novum Jus, 5(2), 9-27.

Llano, J. (2013). Prácticas jurídicas locales desde los actores del conflicto armado en Colombia. Revista IUSTA, 39(2), 257-287.

Naciones Unidas. (2006). Alto Comisionado de las Naciones Unidas para los Derechos Humanos. Estudio sobre el derecho a la verdad. https://www.acnur.org/fileadmin/Documentos/BDL/2010/7967.pdf

Naqvi, Y. (2006). El derecho a la verdad en el derecho internacional: ¿̇realidad o ficción? International Review of the Red Cross, 862. https://www.icrc.org/spa/assets/files/other/irrc 862 naqvi.pdf

Naciones Unidas. (1977). Protocolo I adicional a los Convenios de Ginebra de 1949 relativo a la protección de las víctimas de los conflictos armados internacionales. https://www.icrc.org/es/document/protocolo-i-adicional-convenios-ginebra-1949proteccion-victimas-conflictos-armados-internacionales-1977\#PRE

Naciones Unidas. (1997) Consejo Económico y Social. Informe final revisado acerca de la cuestión de la impunidad de los autores de violaciones de los derechos humanos (derechos civiles y políticos) preparado por el Sr. L. Joinet de conformidad con la resolución 1996/119 de la Subcomisión "La administración de justicia y los derechos humanos de los detenidos”, E/CN.4/Sub.2/1997/20/Rev.1, 2 de octubre de 1997.

Via Inveniendi Et Iudicandi

e-ISSN: 1909-0528 | DOI: https://doi.org/10.15332/19090528

Vol. 16 N.o 1 | enero-junio del 2021 
Organización de los Estados Americanos (OEA), Convención Americana sobre Derechos Humanos "Pacto de San José de Costa Rica”, 22 Noviembre 1969, disponible en esta dirección: https://www.refworld.org.es/docid/57f767ff14.html [Accesado el 7 mayo 2021]

Orjuela, L. (2000). La debilidad del Estado colombiano en tiempo del neoliberalismo y el conflicto armado. Colombia Internacional, 49-50, 103-116.

https://doi.org/10.7440/colombiaint49-50.2000.05

Picarella, L. (2017). El cosmopolitismo de la utopía a la posible implementación práctica. Revista de Filosofía, 86(2), 70-90. https://produccioncientificaluz.org/index.php/filosofia/article/view/31216/

Picarella, L. (2018). Democratic deviations and constitutional changes: The case of Turkey. Academic Journal of Interdisciplinary Studies, 7(2), 9-16.

Rettberg, A. (2005). Reflexiones introductorias sobre la relación entre construcción de paz y justicia transicional. En A. Rettberg (comp.), Entre el perdón y el paredón: preguntas y dilemas de la justicia transicional (pp. 1-18). Ediciones Uniandes; International Development Research Centre.

Rincón, K. y Peñas, A. (2015). El delito político en Colombia frente al derecho internacional humanitario. Revista IUSTA, 43, 67-90. http://revistas.usta.edu.co/index.php/iusta/article/view/2538/2470

Rodríguez, A. (2014). Indicadores de constitucionalidad de las políticas públicas: enfoque de gestión de derechos. Revista Via Inveniendi et Iudicandi, 9(2), 135-175.

Scocozza, C. (2015). La Primera Guerra Mundial. Un conflicto que llega desde el este. Anuario Colombiano de Historia Social y de la Cultura, 42(2), 161-176.

Uprimny, R. y Saffon, M. (2006). Verdad judicial y verdades extrajudiciales: la búsqueda de una complementariedad dinámica. De Justicia. https://www.dejusticia.org/wpcontent/uploads/2017/04/fi name recurso 39.pdf

Uprimny, R. y Saffon, M. P. (2006). Derecho a la verdad: alcances y límites de la verdad judicial. En Justicia transicional: Teoría y praxis. Universidad del Rosario.

Wabgou, M. (2013). Experiencias posconflicto de países africanos: justicia transicional en Ruanda. Revista Novum Jus, 7(1), 31-49.

Zuluaga, M. (2015). ¿Y cómo es posible no saber tanto? Fondo Editorial Universidad EAFIT.

Via Inveniendi Et Iudicandi

e-ISSN: 1909-0528 | DOI: https://doi.org/10.15332/19090528

Vol. 16 N.o 1 | enero-junio del 2021 